\title{
DIE VERBAND TUSSEN WERKNEMERS SE HOUDING JEENS REGSTELLENDE AKSIE EN HUL WERKSBETROKKENHEID: 'N EKSPLORATIEWE STUDIE
}

\author{
S M MÜLLER \\ G ROODT
}

Departement Menslike Hulpbronbestuur

Randse Afrikaanse Universiteit

\begin{abstract}
The relationship between employees' attitudes toward affirmative action and their work involvement: an explorative study. The principal aim of the study was to determine whether or not employee's attitude towards affirmative action bears any relation to their work involvement. A random sample of 600 participants taken from a large insurance company yielded 138 usable questionnaires. Although intercorrelations between attitude towards affirmative action and four work-related involvement foci produced no significant relation, chi square analyses did indicate the possibility of employee's attitude towards affirmative action and their work involvement being moderated by their gender and home language. Subsequently, the implications of these findings are discussed.
\end{abstract}

\section{OPSOMMING}

Die hoofdoel van die onderhawige studie was om te bepaal of daar 'n verband tussen werknemers se houding jeens regstellende aksie en hul werksbetrokkenheid bestaan. 'n Ewekansige steekproef van 600 deelnemers geneem uit 'n groot versekeringsonderneming het 138 bruikbare vraelyste opgelewer. Hoewel interkorrelasies tussen houdings jeens regstellende aksie en vier werkverwante betrokkenheidsfokusse geen betekenisvolle verbande opgelewer het nie, het chi-kwadraatontledings daarop gedui dat werknemers se houding jeens regstellende aksie en hul werksbetrokkenheid moontlik wel deur faktore soos geslag en huistaal gemodereer word. Die implikasies van die bevindinge word vervolgens bespreek.

Die eerste demokratiese en multi-etniese verkiesing van 27 April 1994 het vir duisende Suid-Afrikaners nuwe hoop gebring, maar ook die land se geskiedenis en industriële scenario 'n dramatiese wending laat neem. Benewens hierdie wending het die uitwerking van die regering se regstellende-aksie-beleid ook ál meer voelbaar geword. Werkers het ook algaande tot die besef begin kom dat hoewel regstellende aksie vir duisende van hul medewerkers die eerste kykie op 'n moontlike rooskleurige toekoms verteenwoordig, dit ook 'n tweesnydende strydbyl kan word wat hul eie regmatige toekomsverwagtinge kan verydel. Teen hierdie agtergrond beskou, het die navorsers 'n ondersoek van stapel gestuur om te bepaal of daar reeds ' $n$ verband tussen werknemers se houding jeens regstellende aksie en die graad van hul werksbetrokkenheid aan te toon is.

Suid-Afrikaners huldig tans uiters uiteenlopende menings omtrent regstellende aksie. Sommige beskou dit as blote "omgekeerde diskriminasie", terwyl ander weer meen dat diskriminasie ten spyte van regstellende aksie steeds onverpoosd voortgaan (Easton-Leadley, 1994; Human, 1991). Navorsing het reeds aan die lig gebring dat terwyl regstellende aksie in werklikheid as 'n strategie beskou moet word waarmee diversiteit in die werkplek bevorder kan word, dit meestal nie eens as ' $n$ integrerende deel van 'n groter langtermynplan geag word nie (Ramudzuli \& Mannè, 1994). Die nut en waarde van regstellende aksie word dus deur 'n substansiële gedeelte van die SuidAfrikaanse bevolking bevraagteken.

Uit ' $n$ werkgewersperspektief gesien, definieer die Instituut vir Personeelbestuur (IPB) se "Position Statement on Affirmative Action" (1993), p. 1) regstellende aksie as "'n proses wat gemik is op die transformasie van die sosio-ekonomiese omgewing om sodoende op grond van hul potensiaal aan minderbevoorregte individue (wat in die verlede op grond van biografiese verskille uitgesluit was) toegang tot geleenthede te verleen". Daar word dus bewustelik gepoog om benadeelde groepe ten opsigte van indiensname, ontwikkeling en bevordering binne die organisasie te bevoordeel ten einde tot die holistiese proses van op-

Versoeke vir afdrukke moet gerig word aan SM Müller, Departement Menslike Hulpbronbestuur, Randse Afrikaanse Universiteit, Posbus 524, Aucklandpark 2006 heffing van sodanige groepe by te dra. Ideaal gesien, behoort regstellende aksie te kulmineer in 'n diverse arbeidsmag wat uit werkers van verskillende rasse, kulture, gelowe, ouderdomme, geslagte en seksuele voorkeure bestaan.

Die tagtigerjare se "Black Advancement"-programme het egter meestal misluk (Ramudzuli \& Mannè, 1994) en boonop tot gevolg gehad dat daar selfs minder swartmense ná die implementering van hierdie programme in organisasies oorgebly het. Hoewel hoofsaaklik gebore uit vrees dat wetgewing ingestel word ingevolge waarvan 'n kwotastelsel afgedwing kan word, word die negentigerjare ook deur die instelling van soortgelyke programme onder die dekmantel van "regstellende aksie" ("affirmative action") gekenmerk (Ramudzuli \& Mannè, 1994).

Ernstige probleme is en word steeds met die implementering van regstellende-aksie-programme ondervind. Human en Bowmaker-Falconer (1992) het byvoorbeeld beweer dat regstellende-aksie-programme, ironies genoeg, as gevolg van diskriminasie misluk het. Hulle voer aan dat daar dikwels van swartmense verwag word om suksesvol in "wit" organisasies te funksioneer sonder dat daar enige aanpassings gemaak of bykomende ondersteuning aan hulle gebied word. Om regstellende-aksie-programme suksesvol te implementeer en steeds te verseker dat die arbeidsmag doeltreffend funksioneer, is Andrew Levy en Vennote (1993) en Mbigi (1993) dit eens dat daar geen diskriminerende aktiwiteite of praktyke binne 'n organisasie geduld mag word nie. Ongelukkig wil dit egter voorkom asof regstellende-aksie-programme tans wél as diskriminerend ervaar word, en dat hierdie feit moontlik afbreuk kan doen aan die doel wat uiteindelik daarmee bereik wil word.

By die implementering van regstellende-aksie-programme bestaan daar egter ook 'n wesenlike gevaar dat "simboliese aanstellings" gemaak sal word wat regstreeks tot 'n verlaging van standaarde kan lei (Alperson, 1992; Barnard, 1993; Human, 1993; Wingrove, 1993). Selfs die ywerigste voorstanders van regstellende aksie is pynlik bewus van die verwoesting wat sodanige aanstellings op die lang duur in die ekonomie kan aanrig (Ndlovu, 1993). 
Easton-Leadley (1994) en Mindell (1992) wys op hul beurt daarop dat daar byna sonder uitsondering 'n wye spektrum van uiteenlopende persepsies binne 'n organisasie ontstaan sodra 'n organisasie na benadeelde groepe begin omsien. Enige stappe in hierdie rigting word gewoonlik met groot agterdog deur die arbeidsmag bejeën wanneer die status quo nie meer gehandhaaf word nie, en individue wat tot sodanige histories benadeelde groepe behoort, word dadelik as die bron van die probleem beskou (Mindell, 1992).

Opponerende groepe koester hierbenewens dikwels negatiewe gevoelens teenoor mekaar en is gevolglik nie bereid om enige ander standpunt in te sien nie. Regstellende aksie word só uiteindelik as die brandpunt van alle probleme gesien (EastonLeadley, 1994; Mindell, 1992).

'n Oudit oor bestaande houdings jeens en persepsies oor regstellende aksie het die volgende gevaarpunte geïdentifiseer (Easton-Leadley, 1994):

- Persepsies oor rassisme is deurgaans meer negatief onder swart respondente as onder wit respondente. Sommige swart respondente beweer selfs dat die besture van hul onderskeie organisasies nou in 'n hoër mate as ooit tevore teen hulle diskrimineer.

- Wit respondente voel dikwels dat swart werkers voorkeur geniet en beweer daar is "omgekeerde diskriminasie". Easton-Leadley (1994) is selfs die mening toegedaan dat 'n "white backlash" in reaksie op regstellende aksie nie uitgesluit moet word nie. Verskeie ander skrywers stem hiermee saam as hulle die mening uitspreek dat wit werkers se teenreaksie teen regstellende aksie die grootste enkele bedreiging vir die suksesvolle opheffing van histories benadeelde groepe inhou (Franks, 1987; Hofmeyer, 1993; Hofmeyer \& Templer, 1991; Human, 1993; Human \& Hofmeyer, 1987; Kamfer, 1989; Sonn, 1993; Wingrove, 1993).

- Kleurling-respondente voel egter op hul beurt dat hulle maar steeds aan die verloorkant is, aangesien daar eers onder die Apartheidsbedeling teen hulle gediskrimineer is, en nou weer.

- Swart werkers glo dikwels dat strenger dissipline op hulle toegepas word bloot omdat hulle swart is. In teenstelling hiermee glo wit werkers weer dat geen of min dissipline op swart werkers toegepas word, omdat die bestuur die vakbonde en unies se reaksie daarop vrees.

Daar kan dus sonder vrees vir teëspraak uit die voorgaande afgelei word dat ál die betrokke partye tans 'n mate van diskriminasie ervaar. Innes, Kentridge en Perold (1993) beklemtoon hierdie afleiding wanneer hulle beweer dat individue wat diskriminasie ervaar, gaandeweg 'n gevoel van minderwaardigheid begin koester, wat weer verhinder dat hulle hul volle potensiaal ontwikkel. ' $n$ Verlaging in standaarde, ' $n$ verlies aan produktiwiteit en 'n toename in arbeidsomset is maar drie van die vele reperkussies wat laasgenoemde scenario tot gevolg kan hê. Daar bestaan dus ' $n$ groot moontlikheid dat diskriminasie bloot uit die destruktiewe verhouding tussen "binnegroepe" (dié met mag) en buitegroepe (dié sonder mag) kan voortspruit. 'n Gevoel van mag lei by die een groep tot sekuriteit, terwyl die ander groep toenemend 'n gevoel van magteloosheid ervaar (Ray \& Rimzler, 1994). Magteloosheid word op sy beurt as een van die hoofdimensies van vervreemding beskou (Seeman, 1959).

Onopgeloste probleme as gevolg van diskriminasie gebaseer op biografiese faktore mag in die nabye toekoms hand oor hand toeneem (Mindell, 1992). Hierbenewens word die marginalisasie van minderheidsgroepe as waarskynlik een van die vernaamste oorsake van vervreemding in die moderne samelewing geïdentifiseer.

Die feit dat regstellende-aksie-programme stellings ontlok soos dat daar "geen toekoms binne 'n organisasie is nie" of dat daar "steeds diskriminasie plaasvind," kan gevolglik tot werksver- vreemding lei. Ferndale en Venter (aangehaal deur Ramudzuli \& Mannè, 1994) meen dat wanneer individue regstellendeaksie-programme as bedreigend ervaar, daar 'n groot moontlikheid bestaan dat dié programme voortdurend gesaboteer sal word. Só kan die sabotasie van regstellende-aksie-programme bes moontlik nog as 'n uitvloeisel van werksvervreemding manifesteer.

Navorsers het in die verlede die term "werksvervreemding" op verskillende wyses gedefinieer. Kanungo (1979, pp. 131-133; 1981, pp. 8-9; 1982, p. 76) het daarom gepoog om bestaande definisies te integreer deur 'n motiveringsbenadering tot werksvervreemding en werksbetrokkenheid te volg. Só het Kanungo $(1979$, p. 131) werksvervreemding en werksbetrokkenheid as die twee uiterste pole van 'n bipolêre kontinuum gekonseptualiseer, ingevolge waarvan werksvervreemding en werksbetrokkenheid respektiewelik gedefinieer is as ' $n$ algemene kognitiewe predisposisie van geskeidenheid van werk aan die een kant en 'n algemene kognitiewe predisposisie van identifikasie met werk aan die ander kant. Werksvervreemding kan dus aan die kognitiewe oortuigingstoestand van die werker gekoppel word dat werk nie oor die potensiaal beskik om markante behoeftes te bevredig nie (Kanungo, 1979, p. 131; Roodt, 1991, p. 6; Roodt, Bester \& Boshoff, 1994, pp. 12-13). Vir die doeleindes van die onderhawige studie sal daar met die definisie van Kanungo (1979) volstaan word.

Hoewel geen studies opgespoor kon word wat 'n pertinente verband tussen werkers se houding jeens regstellende aksie en die vlak van hul werksbetrokkenheid aandui nie, word daar wel op grond van die voorafgaande teoretisering 'n verband gepostuleer. Die eksploratiewe aard van die studie word grootliks deur die gebrek aan navorsing op hierdie terrein bepaal.

Die doelstelling van hierdie studie is tweeledig:

Eerstens sal bepaal word of daar ' $n$ verband bestaan tussen werknemers se houding jeens regstellende aksie en hul betrokkenheid by vier werkverwante fokusse, naamlik werk, pos, beroep en organisasie.

Tweedens sal vasgestel word of werknemers se houdings jeens regstellende aksie en hul betrokkenheid by die onderskeie werkverwante fokusse moontlik met sommige biografiese veranderlikes verband hou.

\section{NAVORSINGSMETODE}

Die navorsingsmetode wat in hierdie studie gevolg is, word hieronder bespreek.

\section{Deelnemers}

'n Ewekansige steekproef van 600 respondente is uit 'n populasie van administratiewe personeellede $(\mathrm{N}=2600)$ van 'n Gautengse versekeraar geneem. Van hierdie 600 respondente is 138 ingevulde vraelyste terugontvang, wat 'n responskoers van $23 \%$ verteenwoordig.

Uit die 138 respondente is $60,9 \%$ dames. Die oorgrote meerderheid van die respondente is Engels- of Afrikaanssprekend, en slegs $15,9 \%$ is swarttaalgebruikers. Wat die respondente se gemiddelde ouderdom betref, is $52,2 \% 29$ jaar en jonger. In soverre dit die respondente se huwelikstaat aangaan, is $57,2 \%$ getroud, terwyl 52,2\% van hulle geen afhanklikes het nie. Die stand van die respondente se enkel- of dubbelsalaris-huishoudings is ook gemeet, en dit het aan die lig gekom dat $58 \%$ van hulle nie-alleenbroodwinners is.

Die meeste van die respondente $(59,4 \%)$ het vyf jaar of minder diens. Die meeste respondente (48\%) is op klerklike vlak aangestel. Die grootste groep wat aan die steekproef deelgeneem het, bestaan dus uit jonger mense (gemiddelde ouderdom 32) wat nog nie baie lank in gemelde versekeraar se diens staan nie (gemiddelde aantal diensjare 6,06). Die deelnemers is per gemiddeld 3 jaar in hul huidige poste. 
TABEL 1

BIOGRAFIESE INLIGTING VAN RESPONDENTE $(\mathrm{N}=138)$

\begin{tabular}{|c|c|c|c|c|}
\hline 1 Geslag & $\begin{array}{c}\text { Fre- } \\
\text { kwensie }\end{array}$ & $\begin{array}{c}\text { Persen- } \\
\text { tasie }\end{array}$ & $\begin{array}{c}\text { Gemid- } \\
\text { deld }\end{array}$ & $\begin{array}{l}\text { Standaard- } \\
\text { afwyking }\end{array}$ \\
\hline Manlik & 54 & 39,1 & & \\
\hline Vroulik & 84 & 60,9 & & \\
\hline TOTAAL & 138 & 100 & & \\
\hline
\end{tabular}

\section{Huistaal}

\begin{tabular}{lcc}
\hline Afrikaans & 59 & 42,8 \\
Engels & 57 & 41,3 \\
Ander (swarttaalgebruikers) & 22 & 15,9 \\
TOTAAL & 138 & 100 \\
\hline
\end{tabular}

\begin{tabular}{lcccc}
\hline 3 Ouderdom & & & & \\
\hline $19-29$ & 72 & 52,2 & & \\
Ouer as 30 & 66 & 47,8 & & \\
TOTAAL & 138 & 100 & 32 & 9,41 \\
\hline 4 Huwelikstaat & & & & \\
\hline Nooit getroud nie & 49 & 35,5 & \\
Getroud & 79 & 57,2 & \\
Geskei & 7 & 5,1 & \\
Weduwee/Wewenaar & 3 & 2,2 & \\
TOTAAL & 138 & 100 & \\
\hline
\end{tabular}

\section{Getal afhanklikes}

\begin{tabular}{ccc}
\hline Geen & 72 & 52,2 \\
1 & 24 & 17,4 \\
2 & 25 & 18,1 \\
3 & 13 & 9,4 \\
4 & 4 & 2,9 \\
TOTAL & 138 & 100 \\
\hline
\end{tabular}

\section{Broodwinner}

\begin{tabular}{lcc}
\hline Alleenbroodwinner Ja & 58 & 42 \\
Alleenbroodwinner Nee & 80 & 58 \\
TOTAAL & 138 & 100 \\
\hline
\end{tabular}

\section{Aantal diensjare}

\begin{tabular}{lcccc}
\hline $0-5$ jaar & 82 & 59,4 & & \\
$6-10$ jaar & 31 & 22,5 & & \\
11-15 jaar & 16 & 11,6 & & \\
15 en langet & 9 & 6,5 & & \\
TOTAAL & 138 & 100 & 6,06 & 6,03 \\
\hline
\end{tabular}

\section{Posvlak}

\begin{tabular}{lcc}
\hline Departementshoof & 40 & 29 \\
Afdelingshoof & 22 & 16 \\
Klerk (Ook Graad 0) & 66 & 48 \\
Geen respons & 10 & 7 \\
TOTAAL & 138 & 100 \\
\hline
\end{tabular}

\begin{tabular}{lcccc}
\hline 9 Aantal diensjare in huidige pos & & & \\
\hline $0-5$ jaar & 120 & 87 & & \\
$6-10$ jaar & 11 & 8 & & \\
$11-15$ jaar & 5 & 4 & & \\
15 jaar en langer & 2 & 1 & & \\
TOTAAL & 138 & 100 & 3 & 3,46 \\
\hline
\end{tabular}

\section{Meetinstrumente}

'n Biografiese vraelys is opgestel om die diversiteit van die steekproef uit te lig, sodat verskeie statistiese vergelykings gemakk kan word. Inligting is oor die volgende aspekte ingewin: geslag, huistaal, ouderdom, aantal diensjare, periode in huidige pos, posvlak, huwelikstaat, getal afhanklikes, asook of die individu ' $\mathrm{n}$ alleenbroodwinner is al dan nie.

'n Gewysigde houdingsvraelys oor swart vooruitgang van Barnard (1993) is gebruik, omdat dit houdings jeens regstellende aksie meet wat uit regstellende-aksie-programme voortspruit.

Die vraelys het oorspronklik uit 69 items bestaan. Die doel van die vraelys was om tussen persone met ' $n$ positiewe houding en persone met ' $n$ negatiewe houding jeens regstellende aksie te onderskei. Die volgende wysigings is aan die vraelys aangebring:

- Vir die doeleindes van die onderhawige studie is dié vraelys in Engels vertaal en is die woord "swart" met "disadvantaged groups $s^{\prime 2}$ vervang, aangesien regstellende aksie in hierdie studie na alle minder-bevoorregte groepe verwys, en nie slegs na swartmense nie.

- Hierbenewens is sommige vrae herformuleer om te voorkom dat die vrae sydig voorkom of deur sekere groepe as negatief beskou word, Vyf van die oorspronklike vrae is ook weggelaat, omdat hulle nie op hierdie studie van toepassing is nie (gemelde vrae het byvoorbeeld oor die verblyf van swartmense in wit woongebiede gehandel).

- In die gewysigde vraelys word daar voorts, anders as in die oorspronklike, in die algemeen na bestuur verwys, omdat daar in die populasie wat tans ter sprake is, reeds werknemers van verskillende rasse en geslagte is wat bestuursposte beklee.

Die betroubaarheidskoeffisiënt (Cronbach-alfa) van die oorspronklike instrument was 0,961. Die aangepaste vraelys in die onderhawige studie het 'n Alfakoëffisiënt van 0,97 opgelewer. Die finale vraelys het uiteindelik uit 64 items bestaan.

Vier aangepaste vraelyste oor werkverwante betrokkenheid van Roodt (1993) is gebruik om die verskillende vlakke van werksbetrokkenheid van die steekproef te meet. Die vier vraelyste wat gekies is, konsentreer op die betrokkenheid by die volgende fokusse: werk in die algemeen, pos, beroep en organisasie.

Die interne konstantheid van verkorte weergawes van hierdie vraelyste het bevredigende Alfakoëffisiënte opgelewer, met onderskeidelik $0,81,0,84,0,82$ en 0,89 vir die werk-, pos-, beroeps- en organisasiefokus (Roodt, 1993). Vir die doeleindes van hierdie studie is die vier vraelyste in Engels vertaal en is die item- en responsskaalformaat onderskeidelik na ' $n$ vraag- en ' $n$ intensiteitskaalformaat verander. Die gekombineerde werksbetrokkenheidvraelyste bestaan uit 94 items in totaal, met onderskeidelik 24, 24, 23 en 23 items vir die werk-, pos-, beroeps-en organisasiebetrokkenheidsfokus.

\section{Prosedure}

Die vraelyste is aan sleutelpersone verskaf, wat dit weer aan die respondente uitgedeel het. Die doel van die studie is in ' $n$ dekbrief uiteengesit. Deelname aan die ondersoek het vrywillig en anoniem plaasgevind en respondente is gevra om alle vraelyste (ook dié wat nie ingevul is nie) aan die sleutelpersone terug te besorg. Alle vraelyste is as vertroulik beskou en is in die verseëlde koeverte terugontvang.

\section{Statistiese ontleding}

Alle statistiese ontledings is deur die Randse Afrikaanse Universiteit se Statistiese Konsultasiediens met behulp van BMDPprogramme uitgevoer.

\section{RESULTATE}

Korrelasies tussen die onderskele veranderlikes word in die interkorrelasiematriks in Tabel 2 aangedui: (verwys na die gearseerde gedeelte in Tabel 2)

Uit Tabel 2 hierbo blyk dit dat die houding jeens regstellendeaksie-tellings en die vier werkverwante betrokkenheidsfokussetellings ongekorreleerd is. By nader ondesoek het die strooidiagramme ook aangedui dat daar geen ooglopende kromlynige verbande tussen hierdie veranderlikes bestaan nie. 
TABEL 2

INTERKORRELASIE TUSSEN VERANDERLIKES

\begin{tabular}{|c|c|c|c|c|c|c|c|c|c|c|c|c|c|c|c|}
\hline & & 1 & 2 & 3 & 4 & 5 & 6 & 7 & 8 & 9 & 10 & 11 & 12 & 13 & 14 \\
\hline 1 & Geslag & 1.0000 & & & & & & & & & & & & & \\
\hline 2 & Huistaal & 0.0296 & 1.0000 & & & & & & & & & & & & \\
\hline 3 & Ouderdom & -0.0974 & -0.0816 & 1.0000 & & & & & & & & & & & \\
\hline 4 & Aantal diensjare & -0.0417 & -0.2357 & 0.6535 & 1.0000 & & & & & & & & & & \\
\hline 5 & Aantal diensjare in huidige pos & 0.0286 & -0.1413 & 0.5607 & 0.6032 & 1.0000 & & & & & & & & & \\
\hline 6 & Posvlak & 0.3081 & 0.2207 & -0.4432 & -0.3805 & -0.1032 & 1.0000 & & & & & & & & \\
\hline 7 & Huweliksstaat & 0.0436 & -0.0823 & 0.4414 & 0.3332 & 0.2205 & -0.3028 & 1.0000 & & & & & & & \\
\hline 8 & Aantal afhanklikes & -0.1737 & 0.2245 & 0.3411 & 0.1549 & 0.0320 & -0.1677 & 0.3333 & 1.0000 & & & & & & \\
\hline 9 & Alleenbroodwinner & -0.0209 & -0.1043 & 0.0078 & 0.1108 & 0.1849 & -0.0728 & 0.2674 & 0.0917 & 1.0000 & & & & & \\
\hline 10 & Houding jeens regstellende aksie & -0.1809 & -0.5398 & -0.1348 & -0.1900 & -0.2815 & 0.0360 & -0.1403 & 0,2470 & -0.0919 & 1.0000 & & & & \\
\hline 11 & Werksbetrokkenheid & -0.1254 & 0.1694 & -0.0741 & -0.1689 & 0.0660 & 0.2533 & -0.1237 & 0.0306 & -0.0183 & 0,1132 & 1.0000 & & & \\
\hline 12 & Posisiebetrokkenheid & -0.1112 & 0.1501 & 0.0812 & -0.0098 & 0.1593 & 0.1456 & -0.0572 & -0.0018 & -0.1013 & 0.0464 & -0.6908 & 1.0000 & & \\
\hline 13 & Beroepsbetrokkenheid & -0.1418 & 0.2602 & 0.0091 & -0.1245 & -0.0438 & 0.1330 & -0.1363 & 0.0501 & -0.1011 & 0.2372 & -0.4953 & 0.6889 & 1.0000 & \\
\hline 14 & Organisasieverbondenheid & -0.1457 & 0.0332 & 0.1329 & 0.0959 & 0.2051 & 0.0462 & -0.0233 & 0.0021 & 0.0567 & -0.0928 & -0.4859 & -0.6577 & 0.4775 & 1.0000 \\
\hline
\end{tabular}

TABEL 4

Vervolgens is ' $n$ bondelontleding uitgevoer, ingevolge waarvan die werkverwante betrokkenheidsfokusse-tellings in lae, medium en hoë kategorieë verdeel is ten einde vas te stel of hierdie groepe ten opsigte van hul houding jeens regstellende aksie verskil. Geen beduidende verskille is egter blootgelê nie.

Ten einde die verbande tussen veranderlikes verder te kon ondersoek, is Chi-kwadraatontleding tussen veranderlikes uitgevoer (en na Phi-koëffisiënte getransformeer) en is die volgende verbande tussen die houding van werknemers jeens regstellende-aksie met hul biografiese verandelikes blootgelê (vanweë die beperkings wat ten opsigte van ruimte op hierdie studie van toepassing is, sal slegs statisties beduidende resultate hier bekendgemaak word).

'n Statisties beduidende verband is tussen houding jeens regstellende aksie en geslag $(\varnothing=0,24)$ aangetoon. 'n Phikoëffisiënt bevestig hierdie bevindinge. Proporsioneel meer vroulike respondente het negatief gereageer op vrae oor regstellende aksie as manlike respondente, wat weer deurgaans meer positief gereageer het $\left(\chi_{(\mathrm{gv}=2)}^{2}=8,015 ; \mathrm{p}=0,0182\right)$ (vergelyk Tabel 3).

TABEL 3

DIE VERBAND TUSSEN REGSTELLENDE AKSIE EN GESLAG

\begin{tabular}{lccccc}
\hline \multirow{2}{*}{ Regstellende aksie } & \multicolumn{5}{c}{ Geslag } \\
\cline { 2 - 5 } & \multicolumn{3}{c}{ Manlik } & \multicolumn{2}{c}{ Vroulik } \\
\cline { 2 - 5 } & o & (e) & o & (e) & Totaal \\
\hline Laag (negatief) & 10 & $(17,6)$ & 35 & $(27,4)$ & 45 \\
Medium & 26 & $(21,5)$ & 29 & $(33,5)$ & 55 \\
Hoog (positief) & 18 & $(14,9)$ & 20 & $(23,1)$ & 38 \\
\hline Totaal & 54 & & 84 & & 138 \\
\hline
\end{tabular}

$\chi_{(\mathrm{gv}=2)}^{2}=8,015 ; \mathrm{p}=0,0182$

o - waargenome waarde

(e) - verwagte waarde

$\phi=0,24$

Daar bestaan hierbenewens ' $n$ statisties beduidende verband tussen regstellende-aksie-tellings en huistaal $(\varnothing=0,56)$. Proporsioneel meer Engels- en Afrikaanssprekendes het negatief gereageer op vrae oor regstellende aksie as die swarttaalgebruikers, wat weer in die reël meer positief op dié vrae gereageer $\left(\chi_{(g v=4)}^{2}=43,039 ; p=0,000\right)$ (vergelyk Tabel 4).

Daar is ook 'n statisties beduidende verband tussen werksbetrokkenheid en sommige biografiese veranderlikes aangetoon. Die statisties beduidende verband tussen die werksbetrokkenheidstellings en huistaal het soos volg daar uitgesien: ( $\varnothing$ $=0,29$ ). Proporsioneel meer Engels- en Afrikaanssprekendes was minder by hul werk betrokke as swarttaalgebruikers, wat
DIE VERBAND TUSSEN REGSTELLENDE AKSIE EN HUISTAAL

\begin{tabular}{|c|c|c|c|c|c|c|c|}
\hline \multirow{3}{*}{ Regstellende aksie } & \multicolumn{6}{|c|}{ Huistaal } & \\
\hline & \multicolumn{2}{|c|}{ Engels } & \multicolumn{2}{|c|}{ Afrikaans } & \multicolumn{2}{|c|}{ Swarttaal } & \multirow[b]{2}{*}{ Totaal } \\
\hline & o & (e) & o & (e) & o & (e) & \\
\hline Laag (negatief) & 22 & $(18,9)$ & 22 & $(19,5)$ & 1 & $(6,6)$ & 45 \\
\hline Medium & & $(23,1)$ & 30 & $(23,9)$ & 2 & $(8,0)$ & 55 \\
\hline Hoog (positief) & 12 & $(15,1)$ & 7 & $(15,6)$ & 17 & $(5,3)$ & 36 \\
\hline Totaal & 57 & & 59 & & 20 & & 136 \\
\hline \multicolumn{8}{|c|}{$\begin{array}{l}\chi_{(\mathrm{gv}=4)}^{2}=43,039 ; \mathrm{p}=0,000 \\
\mathrm{o}-\text { waargenome waarde } \\
(\mathrm{e}) \text { - verwagte waarde } \\
\phi=0,56\end{array}$} \\
\hline
\end{tabular}

TABEL 5

DIE VERBAND TUSSEN WERKSBETROKKENHEID EN HUISTAAL

\begin{tabular}{|c|c|c|c|c|c|c|c|}
\hline \multirow{3}{*}{$\begin{array}{l}\text { Werksbetrokken- } \\
\text { heid }\end{array}$} & \multicolumn{6}{|c|}{ Huistaal } & \multirow[b]{3}{*}{ Totaa } \\
\hline & \multicolumn{2}{|c|}{ Engels } & \multicolumn{2}{|c|}{ Afrikaans } & \multicolumn{2}{|c|}{ Swarttaal } & \\
\hline & o & (e) & 0 & (e) & o & (e) & \\
\hline Laag & 20 & $(19,2)$ & 23 & $(20,0)$ & 3 & $(6,8)$ & 46 \\
\hline Medium & 20 & $(20,5)$ & 24 & $(21,3)$ & 5 & $(7,2)$ & 49 \\
\hline Hoog & 17 & $(17,2)$ & 12 & $(17,8)$ & 12 & $(6,0)$ & 41 \\
\hline Totaal & 57 & & 59 & & 20 & & 136 \\
\hline
\end{tabular}

$\chi_{(g v=4)}^{2} 11,427 ; p=0,0222$

$o$ - waargenome waarde

(e) - verwagte waarde

$\phi=0,29$

in die reël meer by hul werk betrokke was $\left(\chi^{2}(\mathrm{gv}=4)=11,427\right.$; $\mathrm{p}$ $=0,0222)$ (vergelyk Tabel 5).

Daar is ook 'n statisties beduidende verband tussen werksbetrokkenheidstellings en posvlak aangetoon $(\varnothing=0,28)$ wat daarop dui dat proporsioneel meer klerke meer werksbetrokke as hul seniors is $\left(\chi^{2}(\mathrm{gv}=4)=9,954 ; \mathrm{p}=0,0412\right)$ (vergelyk Tabel $6)$.

Tussen beroepsbetrokkenheidstellings en huistaal is daar ook ' $n$ statisties beduidende verband blootgelê $(\varnothing=0,37)$. 'n Groter proporsie Engels- en Afrikaanssprekendes was minder beroepsbetrokke as swarttaalgebruikers, wat meer betrokke was $\left.\left(\chi^{2}{ }_{(g v}=4\right)=18,163 ; p=0,0011\right)($ vergelyk Tabel 7.)

Daar is voorts ' $n$ statisties beduidende verband tussen beroepsbetrokkenheidstellings en geslag getrek $(\varnothing=0,28)$. Proporsioneel meer vroue was minder beroepsbetrokke as mans $\left(\chi^{2}(\mathrm{gv}=\right.$ 2) $=10,546 ; p=0,0051)$ (vergelyk Tabel 8 ). 
TABEL 6

DIE VERBAND TUSSEN WERKSBETROKKENHEID EN POSVLAK

\section{Posvlak}

Werksbetrok- Departementshoof Afdelingshoof Klerk

\begin{tabular}{lccccccc}
\cline { 2 - 6 } kenheid & 0 & $(\mathrm{e})$ & 0 & $(\mathrm{e})$ & 0 & $(\mathrm{e})$ & Totaal \\
\hline Laag & 20 & $(14,1)$ & 5 & $(7,7)$ & 20 & $(23,2)$ & 45 \\
Medium & 15 & $(14,1)$ & 8 & $(7,7)$ & 22 & $(23,2)$ & 45 \\
Hoog & 5 & $(11,8)$ & 9 & $(6,5)$ & 24 & $(19,6)$ & 38 \\
\hline Totáal & 40 & & 22 & & 66 & & 128
\end{tabular}

$\left.\chi^{2}(g)=4\right)=9,954 ; p=0,0412$

0 - waargenome waarde

(e) - verwagte waarde

$\phi=0,28$

TABEL 7

DIE VERBAND TUSSEN BEROEPSBETROKKENHEID EN HUISTAAL

\begin{tabular}{lccccccc}
\hline & \multicolumn{6}{c}{ Huistaal } \\
\cline { 2 - 7 } $\begin{array}{l}\text { Beroeps- } \\
\text { betrokkenheid }\end{array}$ & \multicolumn{2}{c}{ Engels } & \multicolumn{2}{c}{ Afrikaans } & \multicolumn{2}{c}{ Swarttaal } \\
\cline { 2 - 7 } & 0 & $(\mathrm{e})$ & 0 & $(\mathrm{e})$ & 0 & $(\mathrm{e})$ & Totaal \\
\hline Laag & 22 & $(17,2)$ & 18 & $(17,8)$ & 1 & $(6,0)$ & 41 \\
Medium & 24 & $(23,9)$ & 27 & $(24,7)$ & 6 & $(8,4)$ & 57 \\
Hoog & 11 & $(16,0)$ & 14 & $(16,4)$ & 13 & $(5,5)$ & 38 \\
\hline Totaal & 57 & & 59 & & 20 & & 136 \\
\hline
\end{tabular}

$\chi_{(\mathrm{gv}=41}^{2}=18,163 ; \mathrm{p}=0,0011$

o-wargenome waarde

(e) - verwagte waarde

$\phi=0,37$

TABEL 8

DIE VERBAND TUSSEN BEROEPSBETROKKENHEID EN GESLAG

\begin{tabular}{lccccc}
\hline & \multicolumn{5}{c}{ Geslag } \\
\cline { 2 - 5 } Beroepsbetrokkenheid & \multicolumn{3}{c}{ Manlik } & \multicolumn{3}{c}{ Vroulik } & \\
\cline { 2 - 5 } & o & $(\mathrm{e})$ & $\mathrm{o}$ & $(\mathrm{e})$ & Totaal \\
\hline Laag & 8 & $(16,0)$ & 33 & $(25,0)$ & 41 \\
Medium & 30 & $(22,7)$ & 28 & $(35,3)$ & 58 \\
Hoog & 16 & $(15,3)$ & 23 & $(23,7)$ & 39 \\
\hline Totaal & 54 & & 84 & & 138 \\
\hline
\end{tabular}

$x^{2}(g i-2)=10,546 ; p=0,0051$

o-wargenome waardes

(c) - verwagte waardes

$\phi=0,28$

Vervolgens is ' $n$ statisties beduidende verband tussen posbetrokkenheidstellings en ouderdom $(\varnothing=0,27)$ aangetoon. Uit hierdie tabel blyk dit dat proporsioneel meer werkers van 30 jaar en ouer minder posbetrokke was as die werkers tussen 19 tot 29 jaar, wat meer neutraal gereageer het $\left(\chi^{2}(g x=4)=10,354\right.$; $\mathrm{p}=0,0349$ ) (vergelyk Tabel 9).

'n Statisties beduidende verband (eenkantig) bestaan tussen posbetrokkenheidstellings en alleenbroodwinnerskap $(\varnothing=$ $0,19)$. Proporsioneel meer alleenbroodwinners was meer posbetrokke as nie-alleenbroodwinners, wat minder posbetrokke was $\left(\chi^{2}(g x=2)=4,735 ; p=0,047\right)$ (vergelyk Tabel 10).

Uit bostaande resultate blyk dit dat huistaal en geslag 'n duidelike verband met sommige werkverwante betrokkenheidsfokusse en houdings jeens regstellende aksie vertoon. Gevolglik is korrelasies tussen werkverwante betrokkenheidsfokusse en houdings jeens regstellende aksie weer bereken waar die taal- en geslaggroepe geskei is.
TABEL 9

DIE VERBAND TUSSEN POSBETROKKENHEID EN OUDERDOM

Ouderdom

\begin{tabular}{lccccc}
\cline { 2 - 5 } & \multicolumn{2}{c}{$19-29$} & \multicolumn{3}{c}{30 en ouer } \\
\cline { 2 - 5 } & 0 & (e) & o & (e) & Totaal \\
\hline Laag & 21 & $(23,5)$ & 24 & $(21,5)$ & 45 \\
Medium & 32 & $(28,2)$ & 22 & $(25,8)$ & 54 \\
Hoog & 19 & $(20,3)$ & 20 & $(18,7)$ & 39 \\
\hline Totaal & 72 & & 66 & & 138 \\
\hline
\end{tabular}

$\chi_{(g y=4)}^{2}=10,354 ; p=0,0349$

a-waargenome waardes

(e) - verwagte waardes

$\phi=0,27$

TABEL 10

DIE VERBAND TUSSEN POSBETROKKENHEID EN ALLEENBROODWINNER

\begin{tabular}{|c|c|c|c|c|c|}
\hline \multirow{3}{*}{ Posbetrokkenheid } & \multicolumn{4}{|c|}{ Alleenbroodwinner } & \multirow[b]{3}{*}{ Totaa } \\
\hline & \multicolumn{2}{|c|}{ Ja } & \multicolumn{2}{|c|}{ Nee } & \\
\hline & 0 & (e) & 0 & (e) & \\
\hline Laag & 13 & $(18,9)$ & 32 & $(26,1)$ & 45 \\
\hline Medium & 26 & $(22,7)$ & 28 & $(31,3)$ & 54 \\
\hline Hoog & 19 & $(16,4)$ & 20 & $(22,6)$ & 39 \\
\hline Totaal & 58 & & 80 & & 138 \\
\hline
\end{tabular}

Slegs een verband (verwys na die gearseerde gedeelte in Tabel 11) het geblyk statisties beduidend te wees, naamlik diê tussen houding jeens regstellende aksie en beroepsbetrokkenheid in gevalle waar slegs dames in ag geneem is $(r(g v-84)=0,2716$; $p$ $=0,05$ ) (vergelyk Tabel 11).

TABEL 11

INTERKORRELASIEMATRIKS VAN VERANDERLIKES: SLEGS DAMES

\begin{tabular}{llrcccc}
\hline & 1 & 2 & 3 & 4 & 5 \\
\hline 1 & Regstellende aksie & 1.0000 & & & & \\
2 & Werksbetrokkenheid & 0.0482 & 1.0000 & & & \\
3 & Posbetrokkenheid & -0.0001 & 0.7045 & 1.0000 & & \\
4 & Beroepbetrokkenheid & 0.2716 & 0.4856 & 0.6691 & 1.0000 & \\
5 & Organisasieverbondenheid & -0.0725 & 0.4982 & 0.7625 & 0.5268 & 1.0000 \\
\hline
\end{tabular}

\section{BESPREKING}

Die navorsing in hierdie studie is eerstens onderneem in ' $\mathrm{n}$ po. ging om te bepaal of daar ' $\mathrm{n}$ verband tussen werkers se houding jeens regstellende aksie en hul betrokkenheid by hul werk ten opsigte van vier werkverwante fokusse, naamlik werksbetrokkenheid, posbetrokkenheid, beroepsbetrokkenheid en organisasie-verbondenheid, bestaan. Geen statisties beduidende verbande is egter blootgele nie.

Tweedens is daar ook gepoog om te bepaal of werkers se houdings jeens regstellende aksie en die onderskeic werkverwante betrokkendheidsfokusse met sommige biografiese veranderlikes verband hou. Die resultate van hierdie studie dui inderdaad daarop dat biografiese veranderlikes die verhouding tussen houding jeens regstellende aksie en vlakke van werkverwante betrokkenheid mag beïnvloed. 
Moontlike tekortkominge van hierdie studie kan soos volg opgesom word:

Tydens die studie is daar veral probleme ondervind met die getal respondente wat bereid was om die vraelyste in te vul. Die oorsaak hiervan kan moontlik toegeskryf word aan:

- die lengte van die vraelyste (baie respondente het slegs gedeeltes van die vraelys ingevul);

- 'n organisasiekultuur wat negatiewe reaksies op regstellende aksie afkeur; en

- die feit dat 'n relatief klein steekproef uiteindelik geneem is en dat die studie by 'n enkele organisasie uitgevoer is, welke feite by die interpretasie van die resultate verreken behoort te word.

$\mathrm{Na}$ aanleiding van die beduidende verbande wat tussen werkers se houdings jeens regstellende aksie en geslag, regstellende aksie en huistaal, beroepsbetrokkenheid en geslag, en beroepsbetrokkenheid en huistaal aangetoon is, is verdere korrelasies bereken wat die interaktiewe aard van taal- en geslagsgroepe bepaal het.

Met inagneming van huistaal en geslag is daar egter steeds slegs een beduidende verband tussen werkers se houdings jeens regstellende aksie en hul beroepsbetrokkenheid blootgelê, naamlik slegs in gevalle waar alleen dames in ag geneem is. Hoewel geen navorsing gevind kan word om hierdie resultate te staaf nie, kan daar moontlik gespekuleer word dat vroue meer negatiewe houdings jeens regstellende aksie inneem en minder beroepsbetrokke as mans voel, omdat hulle moontlik tradisioneel minder geleenthede as mans gehad het en omdat regstellende-aksie-programme nog nie hul situasie dramaties verbeter het nie. Vroue huldig waarskynlik steeds die mening dat mans meer voordele in die werkplek geniet en dat niks as gevolg van hierdie programme verander het nie. Vroue het waarskynlik ook meer gesinsverantwoordelikhede as mans en is daarom moontlik meer bekommerd oor die gevolge van regstellende aksie. Die mans, daarenteen, het moontlik nog nie die volle implikasie van die veranderende beleid ervaar nie, omdat baie van hul manlike rolmodelle steeds hoë bestuursposte beklee. Hierdie persepsie mag moontlik met tyd verander.

Oor die tendens dat Engels- en Afrikaanssprekendes meer negatief voel oor regstellende aksie as die swarttaalgebruikers, kan gespekuleer word dat eersgenoemde groep magteloos en onseker voel oor hul toekoms in die veranderde Suid-Afrika. Of die land hierdie demotiverende uitwerking van regstellende aksie kan bekostig, en die gevolge daarvan onbeperk sal kan absorbeer, is 'n ope vraag. Die gebruikers van Afrika-tale, aan die ander kant, voel positief omdat hulle nou toegang het tot geleenthede wat in die verlede vir hulle ontoeganklik was. Hulle mag moonlik ervaar dat die onregte van die verlede uiteindelik herstel gaan word.

Die feit dat daar geen verband tussen werksbetrokkenheid en ouderdom blootgelê is nie, word ondersteun deur studies soos dié van Batlis (1978); Gechman en Wiener (1975); Kanungo (1982); Knoop (1986) en Mannheim (1975), wat ook geen verband tussen werksbetrokkenheid en ouderdom kon aantoon nie.

Hoewel Roodt (1991; 1993) hoofsaaklik Engels- en Afrikaanssprekendes by sy twee studies in dié verband betrek het, word sy bevindinge gedeeltelik ondersteun deur die verband tussen werksbetrokkenheid en huistaal, wat ook in hierdie studie blootgelê is. Ook die bevindinge van Roodt (1993), naamlik dat daar ' $n$ verband tussen posbetrokkenheid en ouderdom bestaan, word deur hierdie studie ondersteun. Hierdie bevindinge mag ook moontlik meer lig werp op die bevindinge van Lorence (1987); Lorence en Mortimer (1985) en Rabinowitz en Hall (1981) dat werknemers in die stabiliseringsfase van hul loopbane meer betrokke is by hul werk as óf jonger persone in die uittoetsfase óf ouer persone in die instandhoudingsfase van hu loopbane.

Die bevinding van Roodt (1993) dat posbetrokkenheid proporsioneel hoër is by alleenbroodwinners as by nie-alleenbroodwinners word deur hierdie navorsing ondersteun en sluit gedeeltelik aan by die bevindinge van Gould en Werbel (1983) se studie, naamlik dat mans met werkende vroue minder werksbetrokke is as mans wie se vroue nie werk nie. Dit wil dus voorkom asof persone wat nie-alleenbroodwinners is, heelwat minder kwellinge oor inkomste verduur en daarom minder werksbetrokke kan wees.

Die verband tussen werksbetrokkenheid en posvlak weerspreek in 'n hoë mate die navorsing wat deur Mannheim (1975) gedoen is, en ingevolge waarvan ' $n$ verband tussen beroepstatus en werksbetrokkenheid aangetoon is. Die rede hiervoor is dat hierdie studie toon dat proporsioneel meer klerke meer werksbetrokke as hul seniors is. Klerklike poste geniet minder status as departementshoofposte. 'n Moontlike rede waarom klerke in hierdie studie wel meer werksbetrokke kan wees, is omdat hulle nog hoë beroepsverwagtinge koester en hoop dat hulle vinnig in hul loopbane sal vorder.

Verdere navorsing, waarin baie meer klem op die interaktiewe aard van veranderlikes gelê word, kan moontlik duideliker verbande tussen werkers se houding jeens regstellende aksie en werkverwante betrokkenheidsfokusse identifiseer, wat moontlikhede vir toekomstige navorsing inhou. 'n Voorspellingsmodel, waarin die veranderlikes geïdentifiseer word wat moontlik 'n rol kan speel, kan in hierdie opsig van groot waarde wees.

\section{VERWYSINGS}

Alperson, M. (1992). Affirmative Action: The early returns. The Innes Labour Brief, 4(2), 49-63.

Andrew Levy and Associates (1993). Employment Practice and the Bill of Rights. Johannesburg.

Barnard, H.A. (1993). 'n Strategies-kulturele oriëntasie tot die bevordering van die loopbaanmobiliteit van swartes in Suid-Afrika. Ongepubliseerde magistersverhandeling, Johannesburg: RAU.

Batlis, N.C. (1978). Job involvement as predictor of academic performance, Educational and Psychological Measurement 38, $1177-1180$

Easton-Leadley, S. (1994). Managing polarisation: A dose of reality. People Dynamics, 12(10), 44-48.

Franks, P.E. (1987). White resistance to black advancement; empirical findings. SA Journal of Labour Relations, 11(1), 3039.

Gechman, A.S. \& Wiener, Y. (1975). Job involvement and satisfaction as related to mental health and personal time devoted work. Journal of Applied Psychology, 60(4), 521-523.

Gould, S. \& Werbel, J.D. (1983). Work involvement: a comparison of dual-wage earner and single-wage earner families. Journal of Applied Psychology, 68(2), 313-319.

Hofmeyer, K.B. (1993). Affirmative Action in South African companies; Lessons from experience. SA Journal of Labour Relations, 17(11) 36-51.

Hofmeyer, N. \& Templer, A.J. (1991). Comparitive managerial perceptions of progress made in black advancement in South Africa. SA Journal of Labour Relations, 15(2), 3-11.

Human, L. (1991). Advancement, affirmative action and diversity, what South Africa can learn from the USA. IPM Journal, 9 (N12), 11-21.

Human, L. (1993). Affirmative action and the development of people. Kenwyn: Juta.

Human, L. \& Bowmaker-Falconer, A. (1992). Managing Diversity: just another way of avoiding the issue? People Dynamics, 10(9), 25-27, 29.

Human, P.G. \& Hofmeyer, K. (1987). Attitudes of South African managers to the advancement of blacks in business. SA Journal of Labour Relations, 11(3), 5-19.

Innes, D., Kentridge, M. \& Perold, H. (1993). Reversing Discrimination: Affirmative Action in the workplace. Cape Town: Oxford University Press. 
Instituut vir Personeelbestuur. (1993). Position Statement on Affirmative Action. Johannesburg.

Kamfer, L. (1989). Demographic factors affecting white attitudes to black advancement in a South African organisation. Journal of Industrial Psychology, 15(2), 16-20.

Kanungo, R.N. (1979). The concepts of alienation and involvement revisited. Psychological Bulletin, 86(1), 119-138.

Kanungo, R.N. (1981). Work alienation and involvement: problems and prospects. International Review of Applied Psychology, 30 1-15.

Kanungo, R.N. (1982). Work Alienation: An integrative approach. New York: Preager.

Knoop, R. (1986). Job involvement: an elusive concept. Psychological Reports, 59, 451-456.

Lorence, J. (1987). Age differences in work involvement: analysis of three explanations. Work and Occupations, 14(4), 533557.

Lorence, J. \& Mortimer, J.T. (1985). Job involvement through the life course: a panel study of three age groups. American Sociological Review, 50, 618-638.

Mannheim, B. (1975). A comparitive study of work centrality, job rewards and satisfaction. Sociology of Work and Occupations, 2(1): 79-102.

Mbigi, L. (1993). The spirit of African empowerment. People Dynamics, 11(3), 11-14.

Mindell, A. (1992). The Leader as Martial Artist: An Introduction to Deep Democracy. Harper Collins: New York.
Ndlovu, L. (1993). Future Equity. People Dynamics, 11(7), 10-13.

Ramudzuli, A. \& Mannè, L. (1994). Changing Flavour: Affirmative action versus affirmative change. People Dynamics, 12(9), 18-24.

Ray, M. \& Rimzler, A. (1994). The new Paradigm in business. New York: Putman's Sons.

Rabinowitz, S. \& Hall, D.T. (1981). Changing correlates of job involvement in three career stages. Journal of Vocational Behaviour. 18, 138-144.

Roodt, G. (1991). Die graad van werkbetrokkenheid as voorspeler van persoonlike welsyn: 'n Studie by bestuurders. Ongepubliseerde proefskrif, Bloemfontein: Universiteit van die OranjeVrystaat.

Roodt, G. (1993). 'n Ondersoek na die verbondenheid/betrokkenheid by OVS onderwysers. Ongepubliseerde navorsingsverslag, Bloemfontein: Universiteit van die Oranje-Vrystaat.

Roodt, G., Bester, C.L. \& Boshoff, A.B. (1994). Die graad van werkbetrokkenheid: 'n Bipolêre kontinuum? Tydskrif vir Bedryfsielkunde, 20(4), 12-16.

Seeman, M. (1959). On the meaning of alienation. Amercan Sociological Review, 24, 783-791.

Sonn, J. (1993). Changing attitudes and perceptions. Die Suid Afrikaan, 44, 30-31.

Wingrove, T. (1993). Affirmative Action: a practical guide for managers. Pretoria Sigma Press. 